\title{
COMMON SITES OF BLEEDING IN EPISTAXIS
}

\author{
Gaurav Khandelwal', Shobhit Gupta ${ }^{2}$
}

${ }_{1}^{1}$ Associate Professor, Department of ENT, FH Medical College, Etmadpur, Agra, Uttar Pradesh, India.

${ }^{2}$ Assistant Professor, Department of ENT, FH Medical College, Etmadpur, Agra, Uttar Pradesh, India.

\begin{abstract}
BACKGROUND
Epistaxis has historically been classified into anterior and posterior, but no consistent landmark has been used to categories bleeding points. It is very important to know the exact site of bleeding in endoscopic cauterization. However, with the evolution of endoscopic technology, new ways of actively managing epistaxis are now available. Recent evidence suggests that this, combined with the use of stepwise management plans, should limit patient complications and the need for admission.
\end{abstract}

ABSTRACT

\section{METHODS}

This retrospective study was carried out among 102 patients of epistaxis during a 2-year period in the department of ENT. Diagnostic nasal endoscopy was performed in all cases to find the exact site of bleeding. Endoscopic cautery was done in operation theatre.

\section{RESULTS}

In our study, we found that most common site of epistaxis is nasal septum followed by inferior meatus. Then, diagnostic nasal endoscopy was performed with the help of 0 - and 30-degree endoscopes. After finding the exact site of bleeding, endoscopic cauterization was done using bipolar cautery forceps. Patients were closely monitored for 24 hours for recurrence of bleeding.

\section{CONCLUSIONS}

Our knowledge of the most common sites of bleeding from nose in patients will help ENT surgeons to locate the site of epistaxis. Our study will help them in managing epistaxis. Epistaxis is a problem commonly encountered by otolaryngologists. The majority of cases is easily treated, but some may be life-threatening. Knowledge of the vascular anatomy is critical to determine the location of the bleed.

\section{KEY WORDS}

Endoscopic Cauterization, Epistaxis HOW TO CITE THIS ARTICLE: Khandelwal G, Gupta S. Common sites of bleeding in epistaxis. J. Evolution Med. Dent. Sci. 2019;8(26):2055-2058, DOI: 10.14260/jemds/2019/453

\section{BACKGROUND}

Epistaxis is a frequent otolaryngologic emergency. Although most patients can be treated within an accident and emergency setting, some are complex and may require specialist intervention. There are multiple risk factors for the development of epistaxis, and it can affect any age group, but it is the elderly population with their associated morbidity who often require more intensive treatment and subsequent admission. Treatment strategies have been broadly similar for decades. However, with the evolution of endoscopic technology, new ways of actively managing epistaxis are now available. Recent evidence suggests that this, combined with the use of stepwise management plans, should limit patient complications and the need for admission.

At some point in their lifetime, up to $60 \%$ of the population will experience a nose bleed and $6 \%$ of these people will seek medical attention. Epistaxis reportedly occurs more frequently during the dry, cold winter months.

'Financial or Other Competing Interest': None.

Submission 20-04-2019, Peer Review 13-06-2019,

Acceptance 20-06-2019, Published 01-07-2019.

Corresponding Author:

Dr. Shobhit Gupta,

HIG-10, Subhash Chauk,

Main Road, Shaheed Nagar,

Agra-282001, Uttar Pradesh,

India.

E-mail: shobhitsrms@gmail.com

DOI: $10.14260 /$ jemds $/ 2019 / 453$

\section{(c) (i) $\$$}

It is thought to occur more frequently in males than in females, and there is an increasing incidence with age. 1

There are multiple causes of epistaxis which can be divided into local, systemic, environmental, and medication induced. Local causes can include digital manipulation, a deviated septum, trauma, inhaled corticosteroids, and chronic nasal cannula use. Systemic causes can include alcoholism, hypertension, vascular malformations, or coagulopathies (Von Willebrand disease, haemophilia). Environmental factors can include allergies or dryness during winter months. Medications include NSAIDS (Ibuprofen), anticoagulants (Warfarin), platelet aggregation inhibitors (Clopidogrel), or supplement/alternative medications. It is important to consider other aetiologies/malignancies if the patient has red flags such as unilateral nasal blockage, facial pain, headaches, or facial deformity. Drug use (Cocaine) use should be considered in adolescent patients. ${ }^{2,3,4}$

Nosebleeds are due to the rupture of a blood vessel within the richly perfused nasal mucosa. Rupture may be spontaneous or initiated by trauma. The vast majority of nose bleeds occur in the anterior (Front) part of the nose from the nasal septum. This area is richly endowed with blood vessels (Kiesselbach's Plexus). This region is also known as Little's area. Kiesselbach's plexus is an anastomosis with branches from both the internal and external carotid artery systems. The anterior ethmoid, greater palatine, sphenopalatine, and superior labial arteries all form a plexus of vessels in the antero-inferior nasal septum. Kiesselbach's plexus is the source of the majority of nose bleeds. Bleeding farther back in 
the nose is known as a posterior bleed and is usually due to bleeding from Woodruff's plexus, a venous plexus situated in the posterior part of inferior meatus. ${ }^{5}$ It is formed from the anastomoses of the sphenopalatine and pharyngeal arteries. The posterior location makes it a common source for severe, non-traumatic bleeds. Posterior bleeds are often prolonged and difficult to control. They can be associated with bleeding from both nostrils and with a greater flow of blood into the mouth. ${ }^{6}$

In case of posterior epistaxis, the bleeding points cannot be visualized on anterior rhinoscopy because these are located in the deep crevices of the lateral nasal wall or in the posterior part of the nasal cavity. The various sites of bleeding in case of posterior epistaxis include Woodruff's plexus situated on the posterior aspect of the lateral wall of inferior meatus; posterior part of lateral nasal wall near the sphenopalatine foramen; posterior end of inferior turbinate; the middle turbinate and its medial surface; middle and posterior part of septum and floor of nose beneath the inferior turbinate. ${ }^{7}$ The traditional methods of control of posterior epistaxis include antero-posterior packing, nasal balloons and arterial ligation. Of these, nasal packing in the most commonly used method. Apart from the high failure rate of $26-50 \%$ associated with antero-posterior nasal packing, 8 it is associated with marked discomfort, pain and swallowing difficulty and can lead to a large number of local and systemic complications. Local complications include sinusitis, synechiae, otitis media, columellar/alar necrosis, septal perforation, facial oedema, epiphora/dacryocystitis, orbital cellulitis and even cavernous sinus thrombosis. General complications reported include toxic shock syndrome, hypoxia, angina, cardiac arrhythmia, sepsis and even death. As much as $68 \%$ rate of complications has been reported by Wang et al. ${ }^{9}$ Posterior epistaxis is more common in the elderly who cannot tolerate hemodynamic changes because of hypertension, diabetes, COAD and in these patients antero-posterior nasal packing has been associated with a fatal outcome. In view of these problems, patients with antero-posterior nasal packing need hospitalization and constant monitoring. In order to avoid nasal packing, we utilized the technique of posterior endoscopic cauterization which was first described by Wurman et al.10 This can be easily done under local anaesthesia as an OPD procedure, avoids nasal packing, has an excellent patient tolerance, makes hospitalization if required much shorter and has few side effects. Kaluskar ${ }^{7}$ reported an efficacy of $90 \%$. With the uses of endoscope, it is easy for ENT surgeons to find out the exact site of bleeding and cauterize the offending blood vessel endoscopically. If patient having diffuse bleeding, then anterior nasal packing should be the first line of treatment.

\section{METHODS}

This retrospective study was carried out Total Basis Number of 102 patients of epistaxis during the period of 2 year in department of ENT. We took 102 patients of epistaxis which came in ENT emergency during 15 March 2017 to 15 March 2019. Routine investigations were evaluated to find out any systemic cause of epistaxis. Diagnostic nasal endoscopy was performed in all cases to find the exact site of bleeding. Endoscopic cautery was done in operation theatre. Procedure was conducted under local anaesthesia in co-operative patients and general anaesthesia in un-cooperative patients.

\section{RESULTS}

\begin{tabular}{|c|c|c|}
\hline Age (Yrs.) & No. of Patients & Percentage \% \\
\hline $16-20$ & 4 & 3.92 \\
\hline $21-40$ & 23 & 22.49 \\
\hline $41-60$ & 33 & 32.35 \\
\hline $61-80$ & 42 & 41.17 \\
\hline \multicolumn{3}{|c|}{ Table 1. Age Distribution }
\end{tabular}

We took patients whose age ranges between 16 years to 80 years. Most of patients in our study belong to 60 to $80 \mathrm{yrs}$. followed by 40 to $60 \mathrm{yrs}$.

\begin{tabular}{|c|c|c|}
\hline Sex & No. of Patients & Percentage \% \\
\hline Male & 59 & 57.84 \\
\hline Female & 43 & 42.15 \\
\hline \multicolumn{3}{|c|}{ Table 2. Sex Distribution } \\
\hline We selected male and female patient randomly. In our study, we found \\
that male suffered more than female.
\end{tabular}

\begin{tabular}{|c|c|c|}
\hline Site & No. of Patients & Percentage \% \\
\hline Nasal Septum & 48 & 47.05 \\
\hline Inferior Meatus & 16 & 15.68 \\
\hline Roof of Nasal Cavity & 12 & 11.76 \\
\hline Middle Meatus & 11 & 10.78 \\
\hline Floor of Nasal Cavity & 6 & 5.88 \\
\hline Middle Turbinate & 5 & 4.90 \\
\hline Nasopharynx & 4 & 3.92 \\
\hline Anterior Part of Septum & 40 & 83.33 \\
\hline Posterior Part of Septum & 8 & 16.66 \\
\hline
\end{tabular}

Table 3. Site of Epistaxis

A vertical line (Cottle's line) between the nasal process of frontal bone and nasal spine of maxillary crest divides septum into anterior and posterior segments. We found that most of the times bleeding comes from anterior part of septum.

First the nose was packed with roller-gauge soaked in local anaesthetic agent. Then diagnostic nasal endoscopy was performed with the help of 0 - and 30-degree endoscopes. After finding the exact site of bleeding, endoscopic cauterization was done using bipolar cautery forceps. Patients were closely monitored for 24 hours for recurrence of bleeding. Saline nasal drops were advised to patients. Patients who didn't bleed for 24 hours were sent home with the advice that they have to revert back if they have similar episode of epistaxis. No patient had come.

\section{Inclusion Criteria}

1. Patients who were having active bleeding from nose.

2. Patients in which bleeding was not stopped by primary measures.

\section{Exclusion Criteria}

1. Paediatric age group patients.

2. No active bleeding at the time of consultation.

3. Bleeding stopped by primary measures.

4. Patients who were having systemic cause of epistaxis.

5. Patient with history of trauma.

\section{DISCUSSION}

The incidence of epistaxis varies greatly with age. There is a bimodal distribution with peaks in children and young adults and the older adult (45-65 years). ${ }^{11}$ Anecdotal evidence suggests that certain stereotypical groups are more prone (for example, elderly women or young boys). In our study we also saw that maximum no of pt of epistaxis belong to 40-80 age group i.e. $75(73.52 \%)$.

In his Study, Ogah et al ${ }^{12}$ found that out of 49 patients, 26 were males (53.1\%) and 23 were Females (46.9\%) with a male to female ratio of $1.1: 1$. In our study we found that out 
of 102 patients, 59 are males and 43 are females with a male to female ratio is 1.3:1.

We compared our study with article published by Varshneyetal. ${ }^{1}$ In that study, it was found that 50 cases had bleeding from the septum. Out of which in 36 cases, it was from anterior part and in remaining 14 cases, the bleeding was from the posterior part of the septum. While in our study, it was found that 40 patients had bleeding from posterior part of septum and 8 patients had bleeding from anterior part of septum. In their study, 23 cases had bleeding from the lateral wall (12 cases- the inferior turbinate, 11 cases - middle meatus/middle turbinate).while in our study, 21 patients had bleeding from the lateral wall of nose $(16$ patients-inferior meatus and 5 patients -middle turbinate). In their study, 26 cases had bleeding from the nasal floor $(22$ cases from anterior part and 4 cases from posterior part of nasal floor. While in our study, we found that only 6 patients had bleeding from nasal floor.

We did not find any complication with endoscopic cauterization. However, Wurman et al. noticed palatal numbness for several days in some of their patients. This was presumably due to thermal injury to the greater palatine nerve. There is a theoretical possibility of damaging the eustachian tube opening and the nasolacrimal duct in the inferior meatus, but these are avoidable complications.

The most serious complication of nasal packing is posterior dislocation. Reports have been published of fatal aspiration of nasal packs. ${ }^{13}$ Rubber-coated sponge tampons and cotton ribbon gauze packs are liable to dislocate. 14 To prevent this, all nasal packs must be strongly fixed to the patient's face, e.g., with sticking plaster on the bridge of the nose or the cheek.15,16 Additionally, the threads attached to some packs should be tied together in front of the columella. Other reported complications include allergic reaction, mucosal necrosis, foreign body reaction, tube dysfunction, paraffinoma, and decompensation of pre-existing sleep apnea. Nasal packing can also cause discomfort for the patient in the form of pain, obstructed breathing, and a reduced sense of smell. In addition, bilateral nasal packing can result in impaired pressure equalization via the auditory (Eustachian) tube, leading to the patient's discomfort due to negative pressure in the middle ear. There have been case reports of staphylococcal toxic shock syndrome as a serious complication. ${ }^{17-19}$ The release of toxic shock syndrome toxin 1 (TSST1) causes symptoms such as vomiting, diarrhea, fever, myalgia, diffuse erythema, and even septic shock. Treatment consists of immediate removal of the packing, intravenous antibiotics, and transfer of the patient to an intensive care ward. So, we didn't suggest nasal packing in patients of epistaxis.

The role of prophylactic administration of antibiotics with nasal packing has not been adequately studied. Wide variation in practice has been described in England, ${ }^{20}$ e.g., prophylactic antibiotics in patients with cardiac anomalies, especially prosthetic heart valves. ${ }^{21}$ Like some other authors, with anterior nasal packing we recommend prophylactic antibiotics only after the packing has been in place for more than 48 hours, but with posterior packing we recommend it in all cases, with the aim of preventing migration of infection into the sinuses and middle ear and toxic shock syndrome.22 Preferred antibiotics are amoxicillin-clavulanic acid, amoxicillin alone, and cephalosporins. So, we could avoid use of antibiotics in our patients.
One prospective observational study showed a reduction in the number of cases of severe epistaxis in patients taking dabigatran versus vitamin $\mathrm{K}$ antagonists. Hospital stay was longer for dabigatran patients, however, because the lack of an easily available coagulation test and persistent oozing after removal of packing made it necessary to keep the patients under continued observation. ${ }^{23}$ One retrospective study of epistaxis in patients taking rivaroxaban showed a lower percentage of inpatient admissions (10.4\% versus $18.0 \%, \mathrm{p}=0.033)$ and shorter hospital stay $(0.7 \pm 2.2$ versus $1.5 \pm 3.7$ days, $p=0.011$ ) in comparison to patients taking vitamin $\mathrm{K}$ antagonists. ${ }^{24}$ Another risk factor identified was alcohol. One randomized, controlled, double-blind study showed that steroid nasal sprays increase the risk of epistaxis within 12 months in comparison to placebo from $8 \%$ to $20 \%$. The nosebleeds that occurred were slight to moderate; only 1 of 605 patients suffered a severe nosebleed within 12 months. ${ }^{25}$ In a meta-analysis of randomized, controlled studies, epistaxis was reported to be the most frequent undesired effect of PDE-5 inhibitors, with a relative risk of 4.701 (95\% confidence interval [95\% CI]: [1.314; 16.812], $\mathrm{p}=$ 0.017). ${ }^{26}$

Embolisation for epistaxis is a safe and effective method of controlling intractable bleeding. It requires embolisation of bilateral distal internal maxillary artery and unilateral facial artery. ${ }^{27}$ But this is very costly and cumbersome procedure. So direct visualization and cauterization of offending vessel is a better and cheaper procedure, as in our study.

\section{CONCLUSIONS}

Epistaxis is a common condition encountered by otolaryngologists. The majority of cases is easy to treat, but some can become life-threatening. Knowledge of the vascular anatomy is critical to determine the location of the bleed. Treatment strategies have been broadly similar for decades. However, with the evolution of endoscopic technology, new ways of actively managing epistaxis are now available. With the help of endoscope, one can know the exact site of bleeding and do bipolar cauterization. To avoid nasal packing in posterior epistaxis, endoscopic cauterization is recommended as the first line of treatment. This will not only avoid the possible complications and the potentially dangerous antero-posterior nasal packing but may also help in finding the underlying pathology. Our knowledge of most common sites of bleeding from nose in patients will help ENT surgeons to locate the site of epistaxis. Our study will help them in managing epistaxis.

\section{REFERENCES}

[1] Varshney S, Saxena RK. Epistaxis: a retrospective clinical study. Indian Journal of Otolaryngology and Head and Neck Surgery 2005;57(2):125-9.

[2] Mehta N, Stevens K, Smith ME, et al. National prospective observational study of inpatient management of adults with epistaxis - a National Trainee Research Collaborative delivered investigation. Rhinology 2019;57(3):180-9.

[3] Clark M, Berry P, Martin S, et al. Nosebleeds in hereditary hemorrhagic telangiectasia: development of a patient-completed daily eDiary. Laryngoscope Investig Otolaryngol 2018;3(6):439-45. 
[4] Ramasamy V, Nadarajah S. The hazards of impacted alkaline battery in the nose. J Family Med Prim Care 2018;7(5):1083-5.

[5] Chiu TW, Shaw-Dunn J, McGarry GW. Woodruff's plexus. The Journal of Laryngology \& Otology 2008;122(10):1074-7.

[6] Kucik CJ, Clenney T. Management of epistaxis. American Academy of Family Physicians 2005;71(2):305-11.

[7] Kaluskar SK. Endoscopic sinus surgery: a practical approach. London: Springer-Verlag Publisher 1977: p. 107-10.

[8] Pritikin JB, Caldarelli DD, Panje WR. Endoscopic ligation of the internal maxillary artery for treatment of intractable posterior epistaxis. Ann Otol Rhinol Laryngol 1998;107(2):85-91.

[9] Wang L, Vogel DH. Posterior epistaxis: comparison of treatment. Otolaryngol Head Neck Surg 1981;89(6):1001-6.

[10] Wurman LH, Sack JG, Flannery JV Jr, et al. Selective endoscopic electrocautery for posterior epistaxis. Laryngoscope 1988;98(12):1348-9.

[11] Aneeshkumar MK, Osman E, Shahab R, et al. Look before you pack: key point in epistaxis management. Emergency Medical Journal 2005;22(12):912-3.

[12] Ogah SA, Lasebikan T, Owa YE. Epistxis in Lokoja, Nigeria: a review of 49 Cases. SMU Medical Journal 2017;4:26-32.

[13] Kikidis D, Tsioufis K, Papanikolaou V, et al. Is epistaxis associated with arterial hypertension? A systematic review of the literature. Eur Arch Otorhinolaryngol 2014;271(2):237-43.

[14] Viducich RA, Blanda MP, Gerson LW. Posterior epistaxis: clinical features and acute complications. Ann Emerg Med 1995;25(5):592-6.

[15] Viehweg TL, Roberson JB, Hudson JW. Epistaxis: diagnosis and treatment. J Oral Maxillofac Surg 2006;64(3):511-8.

[16] Morgan DJ, Kellerman R. Epistaxis: evaluation and treatment. Primary Care 2014;41(1):63-73.
[17] Walker TWM, Macfarlane TV, McGarry GW. The epidemiology and chronobiology of epistaxis: an investigation of Scottish hospital admissions 19952004. Clin Otolaryngol 2007;32(5):361-5.

[18] McGarry GW, Gatehouse S, Hinnie J. Relation between alcohol and nose bleeds. BMJ 1994;309(6955):640.

[19] McGarry GW, Gatehouse S, Vernham G. Idiopathic epistaxis, haemostasis and alcohol. Clin Otolaryngol Allied Sci 1995;20(2):174-7.

[20] Danielides V, Kontogiannis N, Bartzokas A, et al. The influence of meteorological factors on the frequency of epistaxis. Clin Otolaryngol Allied Sci 2002;27(2):84-8.

[21] Daudia A, Jaiswal V, Jones NS. Guidelines for the management of idiopathic epistaxis in adults: how we do it. Clin Otolaryngol 2008;33(6):618-20.

[22] Stopa R, Schonweiler R. Ursachen von Nasenbluten in Abhängigkeit von Jahreszeit und Wetterlage. HNO 1989;37:198-202.

[23] Garcia CFJ, Becares MC, Calvo GJ, et al. Epistaxis and dabigatran, a new non-vitamin $\mathrm{K}$ antagonist oral anticoagulant. Acta Otorrinolaringol Esp 2014;65(6):346-54.

[24] Sauter TC, Hegazy K, Hautz WE, et al. Epistaxis in anticoagulated patients: Fewer hospital admissions and shorter hospital stays on rivaroxaban compared to phenprocoumon. Clin Otolaryngol 2017.

[25] Rosenblut A, Bardin PG, Muller B, et al. Long-term safety of fluticasone furoate nasal spray in adults and adolescents with perennial allergic rhinitis. Allergy 2007;62(9):1071-7.

[26] Giannetta E, Feola T, Gianfrilli D, et al. Is chronic inhibition of phosphodiesterase type 5 cardioprotective and safe? A meta-analysis of randomized controlled trials. BMC Med 2014;12:185.

[27] Robinson AE, McAuliffe W, Phillips TJ, et al. Embolization for the treatment of intractable epistaxis: 12 month outcomes in a two centre case series. Br J Radiol 2017;90(1080):20170472. 